\title{
Attributions of meteorological and emission factors to the 2015 winter severe haze pollution episodes in China's Jing-Jin-Ji area
}

\author{
Tingting Liu ${ }^{1,2}$, Sunling Gong ${ }^{2,4}$, Jianjun $\mathrm{He}^{2}$, Meng Yu ${ }^{3}$, Qifeng Wang ${ }^{4}$, Huairui Li ${ }^{4}$, Wei Liu ${ }^{3}$, Jie Zhang ${ }^{3}$, Lei Li ${ }^{3}$, \\ Xuguan Wang ${ }^{3}$, Shuli $\mathrm{Li}^{3}$, Yanli $\mathrm{Lu}^{3}$, Haitao Du${ }^{5}$, Yaqiang Wang ${ }^{2}$, Chunhong Zhou ${ }^{2}$, Hongli Liu ${ }^{2}$, and Qichao Zhao ${ }^{4}$ \\ ${ }^{1}$ School of Mechanical Engineering, Hangzhou Dianzi University, Hangzhou, China \\ ${ }^{2}$ State Key Laboratory of Severe Weather \& Key Laboratory of Atmospheric Chemistry of CMA, \\ Chinese Academy of Meteorological Sciences, Beijing, China \\ ${ }^{3}$ Langfang Bureau of Environmental Protection, Langfang, Hebei, China \\ ${ }^{4}$ Langfang Academy of Eco Industrialization for Wisdom Environment, Langfang, Hebei, China \\ ${ }^{5}$ Langfang Bureau of Meteorology, Langfang, Hebei, China \\ Correspondence to: Sunling Gong (sunling@camscma.cn)
}

Received: 5 September 2016 - Discussion started: 21 September 2016

Revised: 23 January 2017 - Accepted: 31 January 2017 - Published: 27 February 2017

\begin{abstract}
In the 2015 winter month of December, northern China witnessed the most severe air pollution phenomena since the 2013 winter haze events occurred. This triggered the first-ever red alert in the air pollution control history of Beijing, with an instantaneous fine particulate matter $\left(\mathrm{PM}_{2.5}\right)$ concentration over $1 \mathrm{mg} \mathrm{m}^{-3}$. Air quality observations reveal large temporal-spatial variations in $\mathrm{PM}_{2.5}$ concentrations over the Beijing-Tianjin-Hebei (Jing-Jin-Ji) area between 2014 and 2015. Compared to 2014, the $\mathrm{PM}_{2.5}$ concentrations over the area decreased significantly in all months except November and December of 2015, with an increase of $36 \%$ in December. Analysis shows that the $\mathrm{PM}_{2.5}$ concentrations are significantly correlated with the local meteorological parameters in the Jing-Jin-Ji area such as the stable conditions, relative humidity $(\mathrm{RH})$, and wind field. A comparison of two month simulations (December 2014 and 2015) with the same emission data was performed to explore and quantify the meteorological impacts on the $\mathrm{PM}_{2.5}$ over the Jing-Jin-Ji area. Observation and modeling results show that the worsening meteorological conditions are the main reasons behind this unusual increase of air pollutant concentrations and that the emission control measures taken during this period of time have contributed to mitigate the air pollution $(\sim 9 \%)$ in the region. This work provides a scientific insight into the emission control measures vs. the meteorology impacts for the period.
\end{abstract}

\section{Introduction}

Severe air pollution has been observed in China for the last 15-20 years, with an annual mean concentration of fine particulate matter $\left(\mathrm{PM}_{2.5}\right)$ ranging from 80 to $120 \mu \mathrm{g} \mathrm{m}^{-3}$ and over $1000 \mathrm{~g} \mathrm{~m} \mathrm{~m}^{-3}$ during some heavy haze episodes. The haze phenomenon has become a major pollution problem in many China cities (Han et al., 2013; Wang et al., 2015), which causes wide public concern and has an adverse impact on human health and the environment (Gurjar et al., 2010; Kan et al., 2012). Therefore, it is necessary to comprehensively investigate the emission sources, meteorological factors, and other characteristics of the $\mathrm{PM}_{2.5}$ pollution in China and provide more effective control measures (Wang et al., 2008; Zhang et al., 2014).

Since the strict control measures of air pollutants over the country were enforced in 2013 by the government, a steady decrease of air pollutant concentrations has been observed with the annual mean $\mathrm{PM}_{2.5}$ concentration dropping

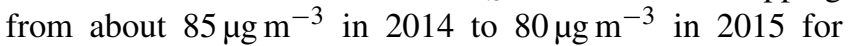
Beijing, from 86 to $70 \mu \mathrm{g} \mathrm{m}^{-3}$ for Tianjin, and from 118 to $88 \mu \mathrm{g} \mathrm{m}^{-3}$ for Shijiazhuang (three typical cities in north China, http://www.mep.gov.cn/gkml/). Meteorological conditions, especially the large-scale circulations, are important factors in determining the variation of pollution levels ( $\mathrm{He}$ et al., 2016a; Jia et al., 2015). Significant regional transport, caused by special meteorological conditions, is critical for 
the formation of severe haze in the winter of 2015 in Beijing (Sun et al., 2016). A number of papers have tried to analyze the meteorological contributions (He et al., 2017; Liao et al., 2015; Wang et al., 2013; Zeng et al., 2014) for individual cases but could not consider the emission changes for a comprehensive analysis. The most recent consensus is that these decreases can be partially attributed to the difference in the meteorological conditions but should largely be attributed to the control measures taken. However, due to the complex interactions between pollution sources and meteorology, the quantitative contributions for each factor remain to be separated.

The year 2015 was an unusual year in terms of the air pollution situation in northern China, which was in the middle of a global El Niño-Southern Oscillation (ENSO) event (Varotsos et al., 2016). Unusual climate and extreme weather happened everywhere. It was found that the El Niño event had a significant effect on air pollution in eastern China (Chang et al., 2016). In the first half of 2015 , a steady decrease in major air pollutants was observed compared to those in 2014 in northern China. However, in the last two months a dramatic increase was observed. The $\mathrm{PM}_{2.5}$ concentration reached as high as $1000 \mu \mathrm{g} \mathrm{m}^{-3}$ in Beijing and triggered the first-ever red alert of severe air pollution in the city. Would this unusual increase of air pollution have anything to do with the special meteorological conditions and the El Niño event? Additionally, what impact did emission control measures have?

This paper presents an analysis and modeling study of air pollution conditions in December 2015 in the BeijingTianjin-Hebei (Jing-Jin-Ji) area located in north China, and it explores the major reasons behind these unusual increases from both the meteorological and emission points of view. To evaluate the contribution of meteorological factors to the severe pollution in December 2015, the wind speed convergence lines (WSCL), the static wind frequency (SWF, wind speed less than $1 \mathrm{~m} \mathrm{~s}^{-1}$ ) data, and other parameters were specifically investigated and compared with data for the same period in 2014. An analysis of this heavy haze pollution episode was also simulated with the Chinese Unified Atmospheric Chemistry Environment (CUACE) model (Gong and Zhang, 2008). The aim of this study was to provide information on the impact degree and the mechanism of meteorology variations and emission changes on the $\mathrm{PM}_{2.5}$ haze pollution in this region.

\section{Methodology}

The research starts with the analysis of air pollution levels between 2014 and 2015 with a focus on the last month of each year. The difference lays the foundation for the investigation, where the meteorology factors that most influence air pollution levels such as stable conditions, wind speed (WS) and direction, and the relative humidity are probed. This provides a qualitative description of the reasons for pol- lution changes from 2014 to 2015. Based on EAR-Interim reanalysis data from the European Centre for Medium-Range Weather Forecasts, the potential effect of ENSO on atmospheric circulation and air quality in the Jing-Jin-Ji area is also thoroughly investigated. In order to quantify the meteorology impacts, a modeling study where the pollution level changes are considered to be caused only by meteorology is carried out with the same emission data for 2014 and 2015 . The impact of emission changes on air pollution due to the meteorology can then be inferred from the difference between the observed pollution level changes and the modeled level changes.

\section{Air quality observations}

The observational pollution data used in this study were from the near real time monitoring stations of the Ministry of Environmental Protection across northern China (http: //www.cnemc.cn/) with hourly concentrations of six major pollutants: particulate matter with an aerodynamic diameter of less than 2.5 and $10 \mu \mathrm{m}\left(\mathrm{PM}_{2.5}\right.$ and $\left.\mathrm{PM}_{10}\right)$, sulphur dioxide $\left(\mathrm{SO}_{2}\right)$, nitrogen dioxide $\left(\mathrm{NO}_{2}\right)$, carbon monoxide (CO), and ozone $\left(\mathrm{O}_{3}\right)$. The monthly and annual mean concentrations of $\mathrm{PM}_{2.5}$ in three typical cities (Beijing, Tianjin, and Shijiazhuang) and the Jing-Jin-Ji area were investigated. The $\mathrm{PM}_{2.5}$ concentration in the Jing-Jin-Ji area is represented by the regional average for the following 13 cities: Beijing, Tianjin, Shijiazhuang, Handan, Xingtai, Hengshui, Cangzhou, Baoding, Langfang, Tangshan, Qinhuangdao, Chengde, and Zhangjiakou. The spatial distribution of the 13 cities is shown in Fig. 1. Based on the wholeyear data for 2014 and 2015, the annual mean concentrations of $\mathrm{PM}_{2.5}$ decreased overall (Fig. 2). For the three typical cities of Beijing, Tianjin, and Shijiazhuang, the annual mean $\mathrm{PM}_{2.5}$ concentrations in 2015 are 5.7, 18.5, and $29.2 \%$ lower than those in 2014, respectively (Fig. 2).

The regional mean $\mathrm{PM}_{2.5}$ concentration over the Jing-Jin$\mathrm{Ji}$ area decreased by $17.8 \%$. The two-year monthly mean $\mathrm{PM}_{2.5}$ concentrations (Fig. 2) show that from January to October, the concentrations in 2015 are much lower than those in the same months in 2014. The unusual increases in $\mathrm{PM}_{2.5}$ concentration are found in the last two months and especially in December, which is the focus of this study.

Regionally, the monthly mean $\mathrm{PM}_{2.5}$ concentrations in December 2015 saw a large increase compared to the same month in 2014, ranging from 5 to $137 \%$ in the Jing-Jin$\mathrm{Ji}$ area with a mean increase of $36 \%$ (Fig. 1). Beijing had the largest increase at $137 \%$, jumping from approximately $61 \mu \mathrm{g} \mathrm{m}^{-3}$ in 2014 to $145 \mu \mathrm{g} \mathrm{m}^{-3}$ in 2015. Qinhuangdao had the smallest increase at $5 \%$, jumping from approximately $69 \mathrm{\mu g} \mathrm{m}^{-3}$ in 2014 to $72 \mu \mathrm{g} \mathrm{m}^{-3}$ in 2015.

Certain factors must have changed dramatically to cause this to happen. In view of the steady decreases of air pollutants over the Jing-Jin-Ji area in the first ten months of 
(a)

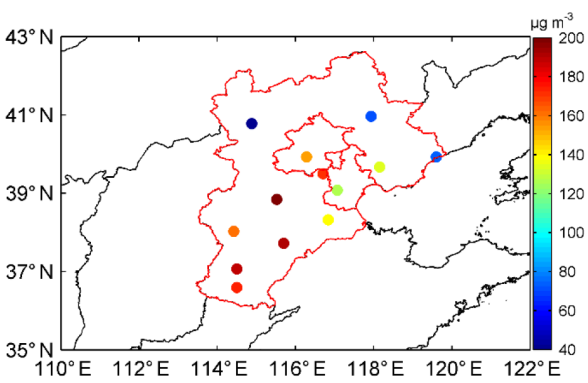

(b)

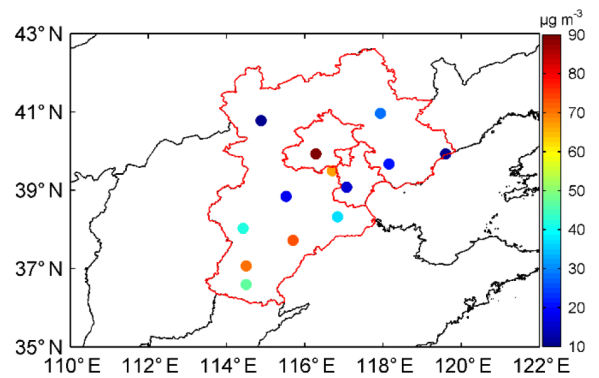

Figure 1. (a) Monthly mean $\mathrm{PM}_{2.5}$ concentrations in December 2015 and (b) the change of monthly mean $\mathrm{PM}_{2.5}$ concentrations in December between 2015 and 2014 over the Jing-Jin-Ji area.
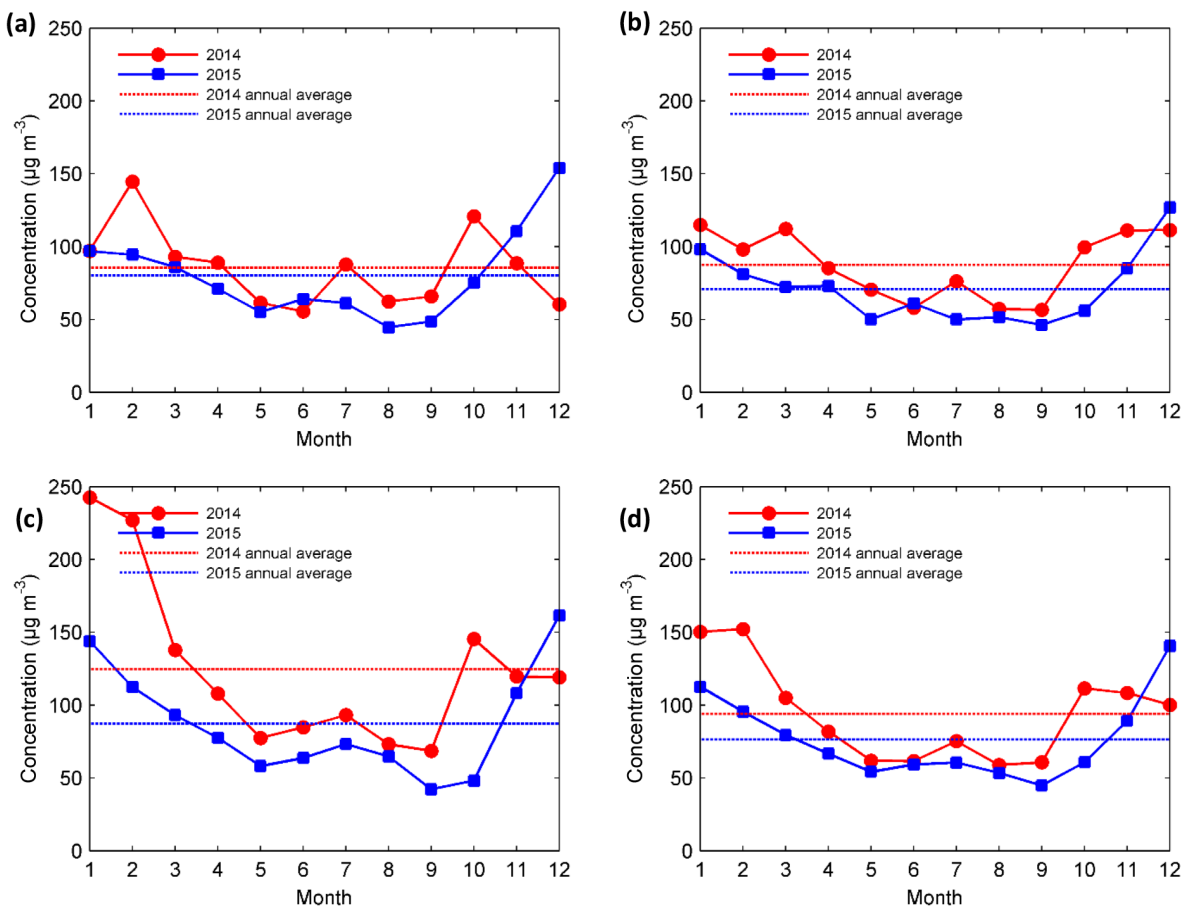

Figure 2. Comparison of monthly average $\mathrm{PM}_{2.5}$ concentrations in 2015 and 2014 in (a) Beijing, (b) Tianjin, (c) Shijiazhuang, and (d) the Jing-Jin-Ji area.

2015, it can be inferred that the emission reduction measures implemented in the region - including traffic restriction, eliminating vehicles that fail to meet the European No. 1 standard for exhaust emission, reducing coal consumption, forbidding straw burning, and reducing volatile organic compounds emission (http://bj.people.com.cn/n/2015/0526/ c233088-25012933.html) - were effective in lowering the average concentrations of major pollutants. In next section, the meteorological conditions in December of 2014 and 2015 will be analyzed in detail to explain the reasons for this dramatic increase in the Jing-Jin-Ji area.

\section{Meteorology factor analysis}

Closely related to air pollution variations, meteorological conditions are important factors in determining day-to-day variations of pollutant concentrations (He et al., 2016a). The correlation between daily average $\mathrm{PM}_{2.5}$ concentrations and four meteorological parameters $-2 \mathrm{~m}$ temperature $\left(\mathrm{T}_{2}\right)$, $2 \mathrm{~m}$ relative humidity $\left(\mathrm{RH}_{2}\right), 10 \mathrm{~m}$ wind speed $\left(\mathrm{WS}_{10}\right)$, and boundary layer height (BLH) - is shown in Fig. 3. The data processing in the correlation calculation is the same as in He et al. (2017). $\mathrm{PM}_{2.5}$ concentrations are positively correlated with $\mathrm{T}_{2}$ and $\mathrm{RH}_{2}$, while negatively correlated with $\mathrm{WS}_{10}$ and BLH. All correlation coefficients $(R \mathrm{~s})$ are significant except $T_{2}$ in Shijiazhuang. The positive correlation be- 


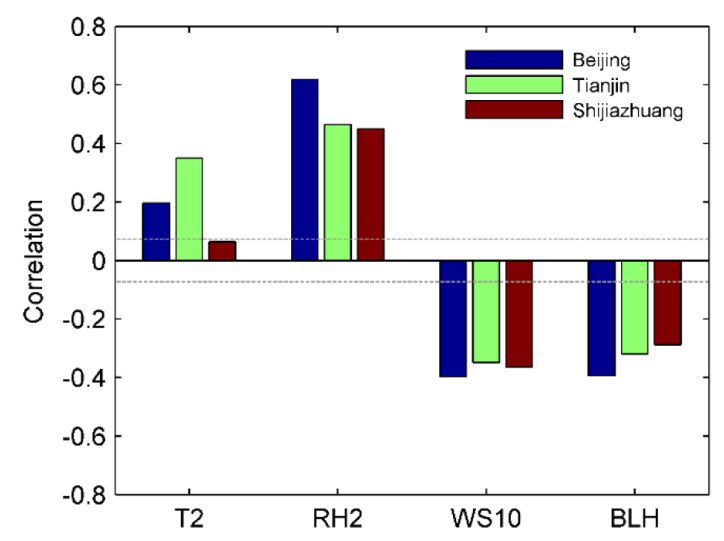

Figure 3. The correlation between daily average $\mathrm{PM}_{2.5}$ concentrations and daily average meteorological parameters during 20142015. The dashed lines represent the critical correlation coefficient that passes the $t$ test at a $95 \%$ confidence level.

tween $\mathrm{PM}_{2.5}$ concentrations and $\mathrm{RH}_{2}$ reveals the importance of hygroscopic growth for PM in the Jing-Jin-Ji area. The increase of $\mathrm{WS}_{10}$ and BLH enhances the ventilation and diffusion capacity and improves air quality. The comparison of the correlation coefficients in the three cities reveals that the local meteorological condition has a more significant effect in Beijing than in Tianjin and Shijiazhuang. Located in the northern edge of the North China Plain, the regional transport of pollutants in Beijing is less complex than in other cities, which may explain the high correlation between $\mathrm{PM}_{2.5}$ concentration and meteorological parameters.

Previous studies have shown that a major factor controlling the pollutant accumulation is the atmospheric stability in association with the convergence at lower levels, which leads to the accumulation of polluted air from the surrounding areas and prevents pollutants from diffusing away from the source regions (Liao et al., 2015; Wang et al., 2013; Zeng et al., 2014). Therefore, the location of the convergence zone is critical in identifying the meteorological conditions that are favorable or unfavorable for the formation of heavy pollution.

Two weather analysis maps are constructed based on average surface meteorological data for December of 2014 and 2015 from the China Meteorological Administration (CMA) (Fig. 4). The mean wind speed for December of 2014 reveals a high wind speed in the Hebei province with a low wind speed in the south of the Hebei province. Wind speed shear, i.e. an abrupt decrease (increase) of wind speed, forms a convergence (divergence) zone that is the WSCL. The WSCL is located at the boundary of the Hebei and Shandong provinces. A serious pollution band near the WSCL will usually form due to the adverse dispersion conditions and pollutant accumulation. Compared to 2014, the WSCL shifted to the Beijing municipality and the center of the Hebei province in 2015. The relocation of the WSCL results in the pollu- tion band moving northward and more serious air pollution in Beijing and the surrounding cities.

Observational evidence has shown a teleconnection between the central Pacific and East Asia during the extreme phases of the ENSO cycles. This Pacific-East Asian teleconnection is confined to the lower troposphere. The key system that bridges the warm (cold) events in the eastern Pacific and the weak (strong) East Asian winter monsoons (EAWMs) is an anomalous lower-tropospheric anticyclone (cyclone) located in the western North Pacific (Wang et al., 2000). Si et al. (2016) found that during the 2015 El Niño period, the EAWM was weaker than normal in the winter, with a temperature increase of $1.1^{\circ} \mathrm{C}$. The subtropical high was stronger and had a larger area than in normal years (Li et al., 2016). As a consequence of the weaker EAWM, the cold front in 2015 could not extend as far south as in 2014 , leading to a northward shift of the WSCL.

Chang et al. (2016) found a close relationship between ENSO and air pollution in north China in 2015. To more deeply investigate the relation between ENSO and the air quality in north China, EAR-Interim reanalysis data from December 1979 to 2015 - including sea surface temperature (SST), mean sea level pressure (MSL), $2 \mathrm{~m}$ temperature $\left(\mathrm{T}_{2}\right)$, and $10 \mathrm{~m} U$ and $V$ wind components $\left(U_{10}\right.$ and $\left.V_{10}\right)$ - were used. Area averaged SST anomalies (SSTAs) over the Nino3 region $\left(5^{\circ} \mathrm{N}-5^{\circ} \mathrm{S}, 150-90^{\circ} \mathrm{W}\right)$ provide an index typically used to represent ENSO variability (Tang et al., 2016). Time series of monthly averaged SSTAs over the Nino3 region are shown in Fig. S3. Significant ENSO events were found in 1982, 1997, and 2015. The MSL and $10 \mathrm{~m}$ wind anomalies over the north China region are shown in Fig. 5. It seems that ENSO (SSTA $>0)$ results in weak cold air and northerly wind while opposite is seen for La Niña (SSTA $<0)$. These relations indicate that the worse air quality seen in December 2015 over north China may be related to the significant ENSO. Further study with longer-period data is needed to investigate this correlation.

There are three consequences of the WSCL shift. The first consequence is the shifting of the stable atmosphere zone to the central Hebei and Beijing areas in 2015, allowing the pollutants to easily accumulate along the WSCL. The observed static wind frequency distribution clearly supports this observation. Figure 6a is the regional distribution of SWF in December 2015 showing a high frequency along the convergence line, with the SWF changes from 2014 shown in Fig. 6b. Table 1 lists the SWF for the three typical cities and the regional mean over the Jing-Jin-Ji area. Except for Shijiazhuang, which had an unusually high SWF in 2014 and a decreasing SWF in 2015, the cities experienced an increasing trend for stable weather. Impacted heavily by the WSCL shift, Beijing and Tianjin had a 16-19\% increase in SWF in 2015 compared to 2014. Even with a decreasing trend for SWF, Shijiazhuang had a similar SWF to the other cities, with more than half of the days $(>50 \%)$ under static stable environment. 


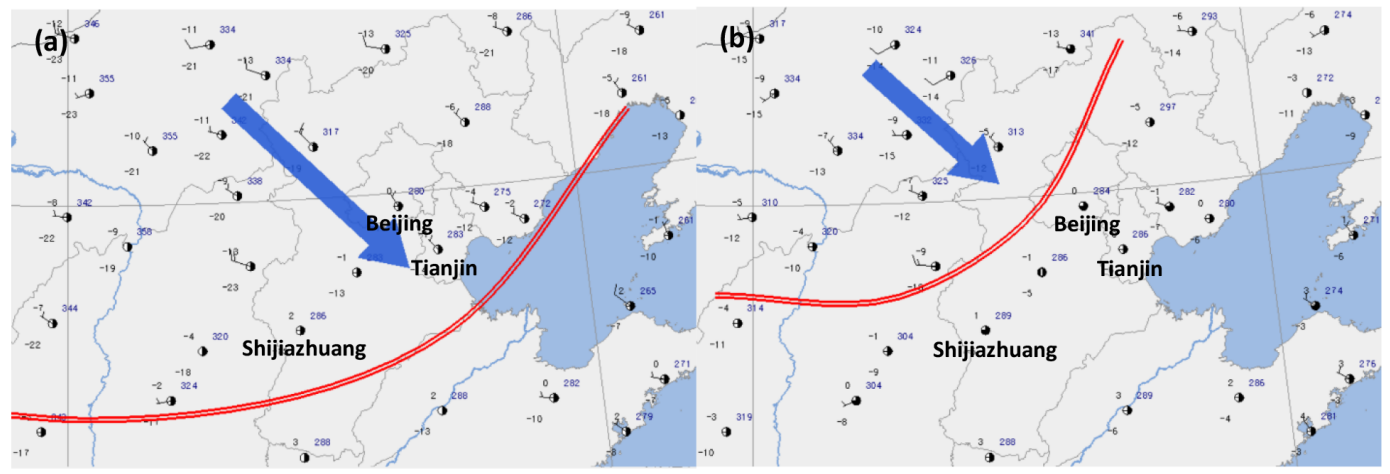

Figure 4. The weather analysis maps in December 2014 (a) and 2015 (b). Red line represents WSCL.

(a)

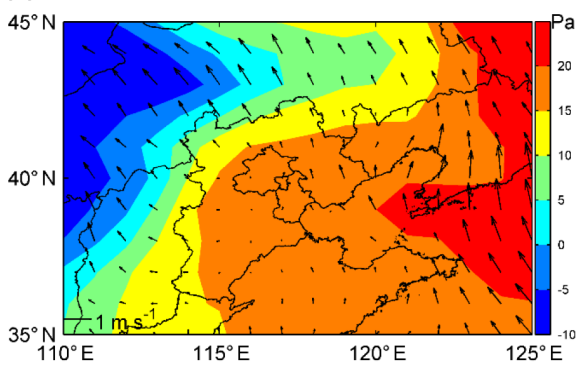

(b)

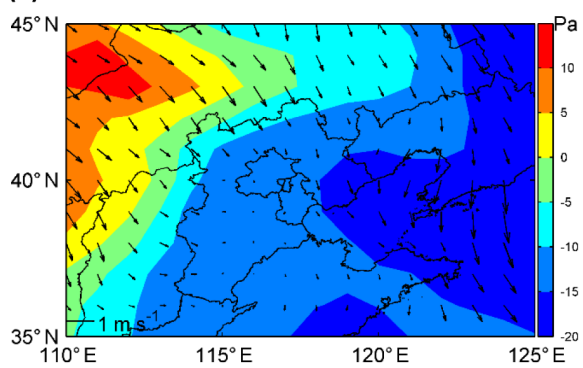

(c)

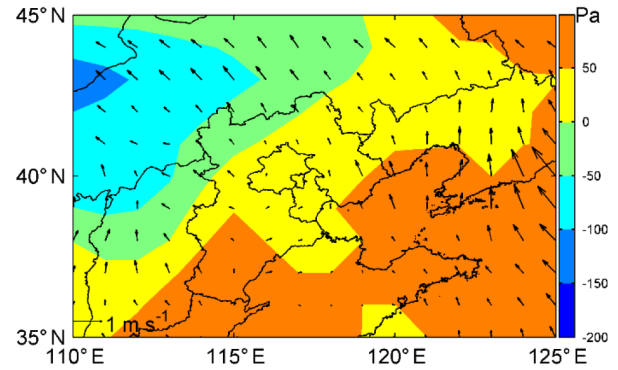

Figure 5. The MSL and $10 \mathrm{~m}$ wind anomalies over the north China region. (a) SSTA larger than zero; (b) SSTA less than zero; (c) December 2015 .

In Beijing, the WSCL shift in December 2015 not only increased the SWF but also changed the wind directions. Figure 7 shows that the northwest winds that usually diffuse air pollution away from Beijing were reduced by about $20 \%$ while the southerly wind frequencies that brought air pollution to Beijing were increased by $8 \%$ in December 2015 compared to the same period in 2014. Compared to Beijing, the city of Shijiazhuang did not see such a large change (Fig. 7). The SWF in Shijiazhuang was reduced and the northerly wind frequency increased by $6 \%$ in December 2015 .

The second consequence of the WSCL shift is the northerly movement of moisture from the south. Figure $6 \mathrm{c}$ and $\mathrm{d}$ show the average $\mathrm{RH}_{2}$ for December of 2015 and the changes from 2014, respectively. It is obvious that as the
WSCL shifts to the north, the RH increases are primarily on the northern side of the WSCL with an increase of $30 \%$ in Beijing (other cities in Table 1). $\mathrm{PM}_{2.5}$ concentration is positively correlated with $\mathrm{RH}_{2}$ (Fig. 3). The increasing $\mathrm{RH}$ has an adverse influence on the visibility under the same loading of particulate matter and promotes the secondary formation of particulate matter from gaseous species. Because of the WSCL shift, the increase in RH in Shijiazhuang was slightly larger than in Beijing, at about $32 \%$. Researchers (Chang et al., 2009) have shown that the extent of $\mathrm{SO}_{2}$ oxidation to sulfate and $\mathrm{NO}_{2}$ oxidation to nitrate increased with the increase of relative humidity during two episodes of daytime and nighttime pollution in Taiwan. Gund et al. (1991) found that the oxidation rate of $\mathrm{SO}_{2}$ to sulfate would increase by about 10 times if the relative humidity increased from 40 to $80 \%$ 
Table 1. Comparison of SWF (\%), WS $10\left(\mathrm{~m} \mathrm{~s}^{-1}\right)$, and $\mathrm{RH}_{2}(\%)$ for December of 2015 and 2014.

\begin{tabular}{lrrr|rrr|rrr|rrr}
\hline City & \multicolumn{3}{c|}{ Beijing } & \multicolumn{3}{c|}{ Tianjin } & \multicolumn{3}{c|}{ Shijiazhuang } & \multicolumn{3}{c}{ Jing-Jin-Ji } \\
\cline { 2 - 13 } & $\mathrm{SWF}$ & $\mathrm{WS}_{10}$ & $\mathrm{RH}_{2}$ & $\mathrm{SWF}$ & $\mathrm{WS}_{10}$ & $\mathrm{RH}_{2}$ & $\mathrm{SWF}$ & $\mathrm{WS}_{10}$ & $\mathrm{RH}_{2}$ & $\mathrm{SWF}$ & $\mathrm{WS}_{10}$ & $\mathrm{RH}_{2}$ \\
\hline 2014 & 35 & 1.5 & 34 & 25 & 1.1 & 40 & 63 & 0.7 & 31 & 38 & 1.4 & 42 \\
2015 & 54 & 0.5 & 64 & 41 & 0.6 & 68 & 55 & 0.6 & 63 & 50 & 0.8 & 67 \\
\hline
\end{tabular}
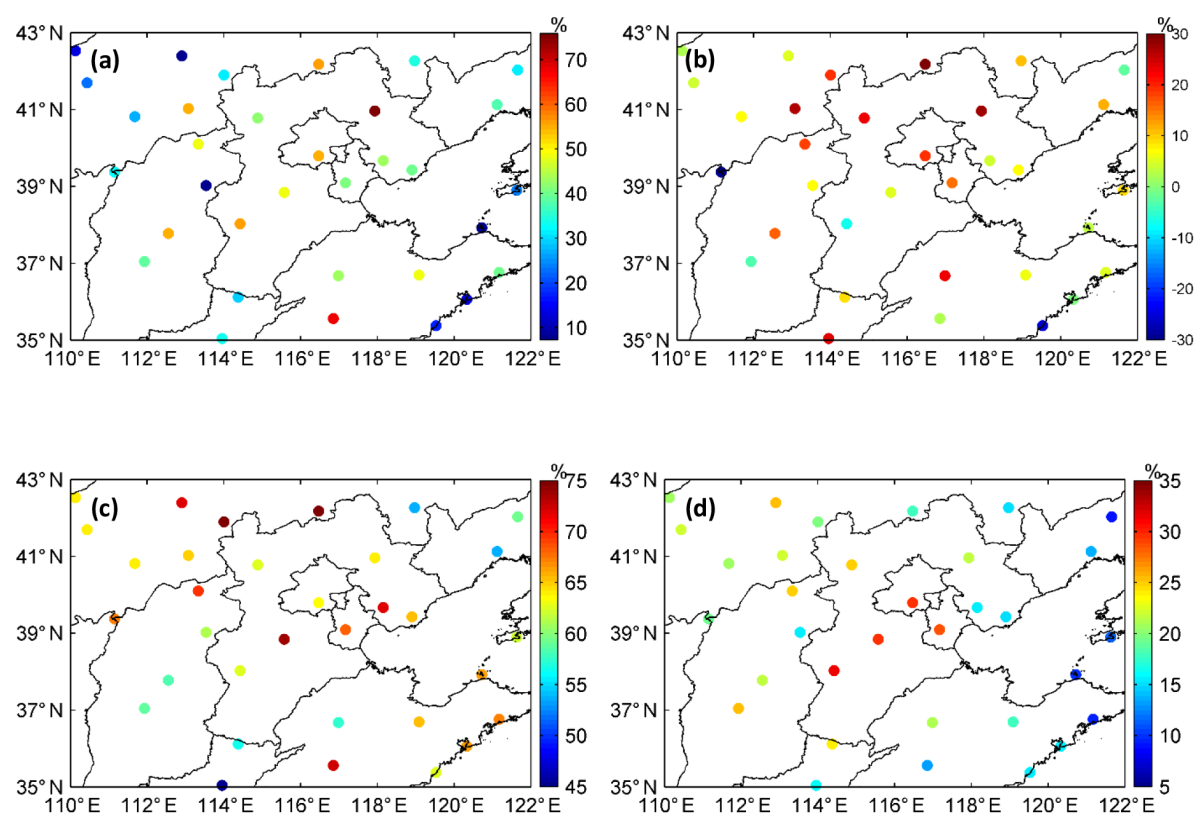

Figure 6. The observed SWF and $\mathrm{RH}_{2}$ distribution average for December 2015 (a, c); Changes from 2014 (b, d).

in sea-salt aerosols. If $\mathrm{NO}_{2}\left(\mathrm{SO}_{2}: \mathrm{NO}_{2}=1: 1\right)$ were added to the gas phase, the rate of conversion of $\mathrm{SO}_{2}$ to $\mathrm{PM}_{2.5}$ at a relative humidity of $40 \%$ would be increased by about 24 times (Gund et al., 1991). Though the detailed mechanism of this enhanced oxidation in northern China needs further study, the increased relative humidity may partially be attributed to the decrease of $\mathrm{SO}_{2}$ (from 86 to $61 \mu \mathrm{g} \mathrm{m}{ }^{-3}$ in the Jing-Jin-Ji area) during the heavy pollution months in the winter of 2015 as compared to the same period of 2014.

The third consequence of the WSCL shift is the decrease of the BLH. Previous research (Liu et al., 2010) has revealed that the invasion of cold air increases the turbulence flux and the BLH over the Beijing area. Compared to 2014, the weaker cold air in December 2015 resulted in a decrease of BLH in the range of 50 to $300 \mathrm{~m}$ over the Jing-Jin-Ji area (Fig. 8), which was one of the main reasons for heavy haze pollution in December 2015.

\section{Modeling analysis}

In order to further explore and quantify the meteorological impacts on the changes of the air pollution situation between December of 2014 and 2015, a comparison of the two years' simulations with the same emission data was performed for December. The difference in the simulated pollutants concentrations can be attributed to the difference impacted by the meteorological conditions.

The CUACE is an atmospheric chemistry module that includes an emission modeling system, gaseous and aerosol processes, chemistry processes, and related thermodynamic equilibrium modules for processing the transformation between gas and particulate matter (Gong et al., 2003; Wang et al., 2010; Zhou et al., 2012). The meteorological model coupled to CUACE is the fifth-generation Penn State/NCAR mesoscale model (MM5). The MM5/CUACE model system was run with three nested domains (a horizontal resolution of 27,9 , and $3 \mathrm{~km}$ ) to reduce spurious inner domain boundary effects (Fig. S1). In the vertical, there are a total of 35 full sigma levels extending to the model top at $10 \mathrm{hPa}$ with 16 levels below $2 \mathrm{~km}$. One month (December) was simulated for 2014 and 2015 with the result differences presented for the analysis. The comparison of the CUACE emission inventory (representing the emission in 2013) to other inventories and the details of the integration scheme, initial condition, and boundary conditions were presented in He et al. (2016b). 
(a)

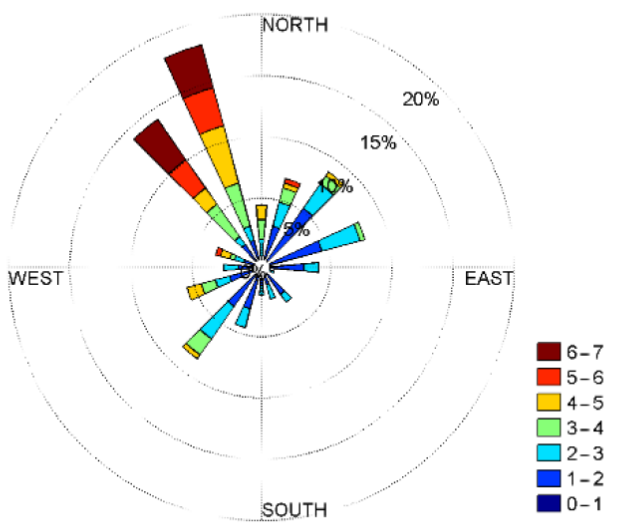

(c)

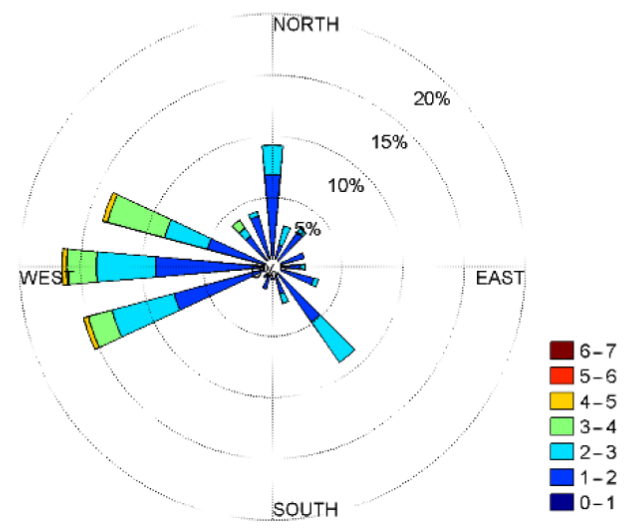

(b)

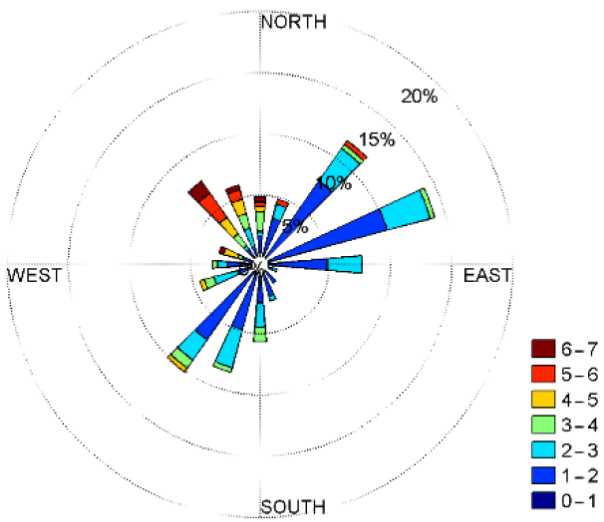

(d)

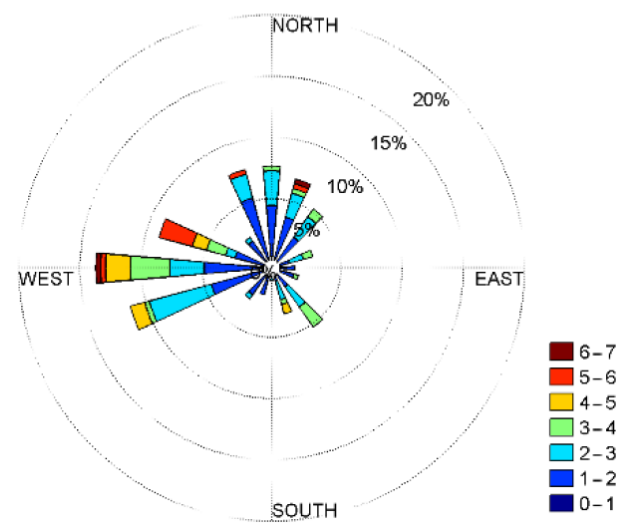

Figure 7. (a) The observed wind frequency and direction averaged in December of 2014 and 2015 in Beijing (a, b) and Shijiazhuang (c, d) respectively.
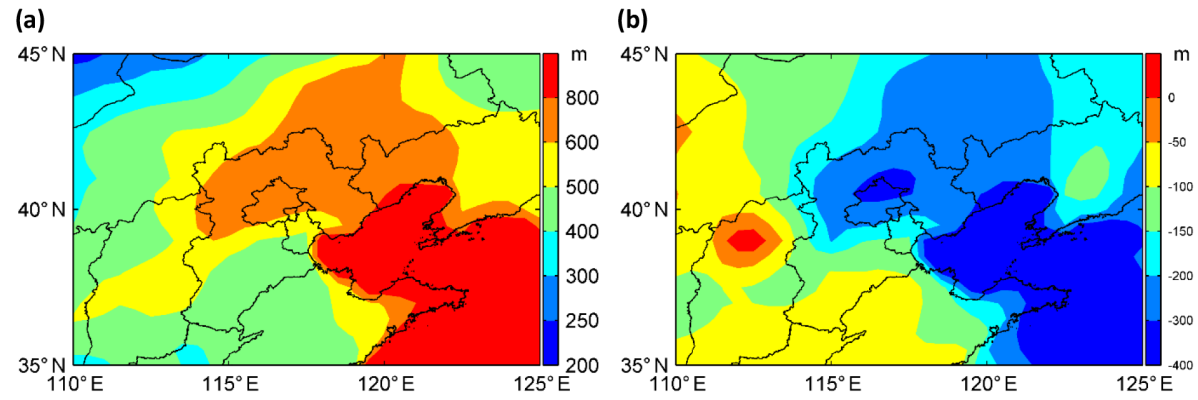

Figure 8. (a) The monthly mean BLH in December 2014 and (b) the change of monthly average BLH in December between 2015 and 2014 over north China.

Six statistical indices - index of agreement (IOA), correlation coefficient $(R)$, standard deviation (SD), root mean square error (RMSE), mean bias (MB), and mean error (ME) - were employed to investigate the performance of MM5/CUACE with the routine meteorological data from the CMA and hourly average $\mathrm{PM}_{2.5}$ concentrations from the Ministry of Environmental Protection. The statistical performance based on hourly observed data were provided in Tables S1 and S2 for MM5 and CUACE, respectively. Direct comparisons between the observed and simulated daily aver- 

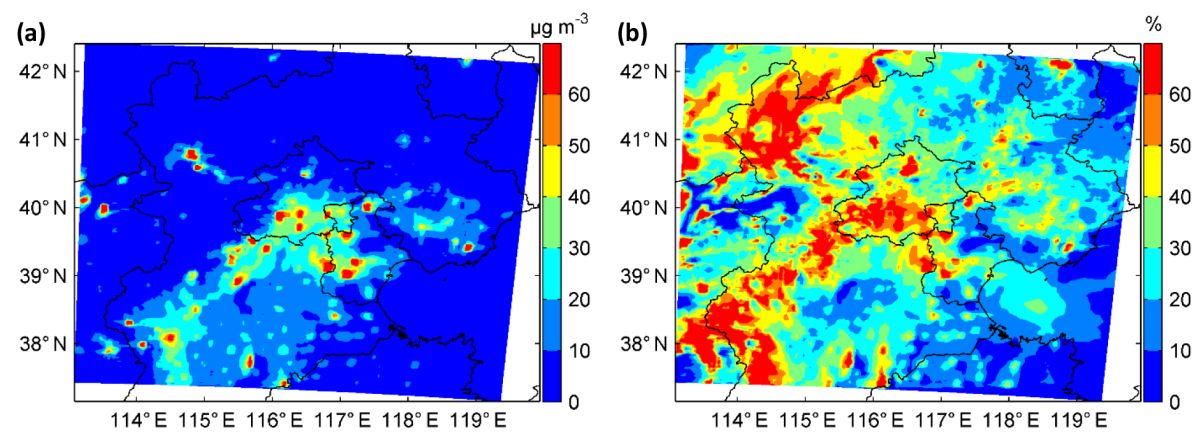

Figure 9. (a) Simulated $\mathrm{PM}_{2.5}$ concentrations difference between December of 2015 and 2014. (b) $\mathrm{PM}_{2.5}$ fractional difference.

age $\mathrm{PM}_{2.5}$ concentrations are shown in Fig. S2. The error in December 2015 is larger than in December 2014, which may relate to the uncertainty of the emission inventory that represents the emission in 2013. The MB of $\mathrm{PM}_{2.5}$ reached 25$30 \mu \mathrm{g} \mathrm{m}^{-3}$ in the simulation for July and December of 2013 (He et al., 2016b), while it decreases to 19 and $17 \mu \mathrm{g} \mathrm{m} \mathrm{m}^{-3}$ for December of 2014 and 2015 respectively (Table S2). This indicates that the emission in the CUACE model might be overestimated considering the gradual emission reduction in recent years. The error of simulated meteorological fields is another important source for the error of simulated $\mathrm{PM}_{2.5}$ concentrations. Generally, the MM5/CUACE model can reproduce the variation characteristics of meteorological parameters and air pollution well, and it is comparable to previous studies (He et al., 2016b; Kioutsioukis et al., 2016).

Figure 9a shows the December $\mathrm{PM}_{2.5}$ concentration difference between 2015 and 2014. It is clear that the meteorological conditions alone have contributed to the worsening air quality $\left(\mathrm{PM}_{2.5}\right)$ in northern China, with a high degradation of about $30-60 \mu \mathrm{g} \mathrm{m}^{-3}$ in the southern Beijing and southern Hebei regions in December 2015. This corresponds well with the WSCL from the surface meteorological data analysis (Fig. 4), which shows the more stable zone moving to closer to southern Beijing.

From the modeling results, it can be seen that the $\mathrm{PM}_{2.5}$ difference (i.e., the concentration difference between December 2015 and 2014 divided by the average concentration in December 2014) due to meteorological difference between December 2014 and 2015 for the major cities in the Jing-Jin$\mathrm{Ji}$ area is in the range of $10-150 \%$ (Fig. 9b). This shows a system-wide negative impact on air quality in the region in 2015. This simulated difference is a comprehensive consequence of the meteorological impacts including circulation, dispersing ability, deposition, transports, and chemical reactions.

It is well known that the $\mathrm{PM}_{2.5}$ concentrations are determined by three major factors: emissions, meteorology, and atmospheric processes. Given that the degree of meteorological impacts was simulated by the model and the observed differences between December 2014 and 2015 were known, the impact from emission changes can be inferred from the
Table 2. Comparison of observed and simulated $\mathrm{PM}_{2.5}$ in December 2015 and 2014.

\begin{tabular}{lrrr|rrr}
\hline \multirow{2}{*}{ City } & \multicolumn{2}{c|}{$\begin{array}{c}\text { Observed } \mathrm{PM}_{2.5} \\
\left(\mu \mathrm{g} \mathrm{m}^{-3}\right)\end{array}$} & \multicolumn{3}{|c}{$\begin{array}{c}\text { Simulated } \mathrm{PM}_{2.5} \\
\left(\mu \mathrm{g} \mathrm{m}^{-3}\right)\end{array}$} \\
\cline { 2 - 7 } & 2014 & 2015 & Diff $(\%)$ & 2014 & 2015 & Diff (\%) \\
\hline Beijing & 61 & 145 & 137 & 68 & 114 & 68 \\
Tianjin & 113 & 125 & 10 & 92 & 129 & 40 \\
Shijiazhuang & 121 & 158 & 30 & 83 & 125 & 51 \\
Jing-Jin-Ji & 102 & 139 & 36 & 82 & 119 & 45 \\
\hline
\end{tabular}

observed differences and the simulated meteorological impacts.

Table 2 is a summary of the differences for the major cities in the Jing-Jin-Ji area between December 2014 and 2015. The observed percentage changes are all lower than the simulated ones except for Beijing. This indicates that if no emission control measures were taken during this period, the observed difference would be much larger. Therefore, it can be deduced that despite the unfavorable weather conditions that worsened the air quality in December 2015, the control measures have greatly contributed to the reduction in the ambient concentrations by about $9 \%$ in the Jing-Jin-Ji area. The increase of the relative variation of the simulated $\mathrm{PM}_{2.5}$ concentration for December between 2015 and 2014 in Beijing is larger than the observed value, which might be related to the bias of the local wind field. In fact, it is very difficult for the mesoscale meteorological model to accurately capture the local wind fields. The comparison of the wind rose map between observation and simulation in December 2015 over Beijing (Fig. S4) reveals that MM5 overestimated the frequency of northwesterly winds, which results in the underestimation of regional transport and $\mathrm{PM}_{2.5}$ concentration in the model. This can explain why there is a difference in the relative change of $\mathrm{PM}_{2.5}$ in Beijing and other cities (Table 2). Another factor that needs further investigation is the observational data quality itself, which may have a large uncertainty associated from different stations and may influence the accurate assessment of the impact. 


\section{Conclusions}

The meteorological data analysis and modeling study of heavy haze pollution episodes in the winter of 2015 were carried out to explore the causes of the unusual increase of haze $\left(\mathrm{PM}_{2.5}\right)$ in December. It was discovered that the monthly mean $\mathrm{PM}_{2.5}$ concentrations in December 2015 saw a large increase compared to the same month in 2014, ranging from 5 to $137 \%$ in the Jing-Jin-Ji area with a mean increase of $36 \%$. Due to the unusual atmospheric circulation in the winter of 2015 (El Niño event), the warm and wet flow was enhanced in north China and the WSCL shifted northerly compared to 2014. The SWF and $\mathrm{RH}_{2}$ increased by 12 and $25 \%$ in the Jing-Jin-Ji area, respectively. These changes of meteorology brought more static stable weather, which was primarily responsible for the degradation of air pollution in the winter of 2015. The modeling analysis further confirmed that the meteorological conditions contributed to the worsening air quality in the Jing-Jin-Ji area in the winter of 2015, with the $\mathrm{PM}_{2.5}$ concentration for the major cities in December 2015 increasing by $45 \%$ compared to the same period in 2014 . In the modeling study with the same emission data for 2014 and 2015 , the relative changes in pollution level between the two years were larger than those from the observation. This indicates that the control measures to compensate for the negative meteorological impacts have effectively brought the $\mathrm{PM}_{2.5}$ concentration down $(\sim 9 \%)$.

Data availability. The air quality dataset used in this study is from the Ministry of Environmental Protection of China (http://www. cnemc.cn/) and can be accessed via https://www.zq12369.com/. The meteorological observation dataset can be acquired from the China Meteorological Data Service Center (http://data.cma.cn/en). The European Centre for Medium-Range Weather Forecasts' ERA data is available from the ECMWF Public Datasets web interface (http://apps.ecmwf.int/datasets/).

\section{The Supplement related to this article is available online at doi:10.5194/acp-17-2971-2017-supplement.}

Competing interests. The authors declare that they have no conflict of interest.

Acknowledgements. This research was financially supported by the Science and Technology support program (2014BAC16B03) and by the National Natural Science Foundation of China (No. 51305112 and 91544232).

Edited by: T. Zhu

Reviewed by: three anonymous referees
References

Chang, L. P., Yao, Y. C., Liao, C. F., Chiang, S. W., and Tsai J. H.: Influence of ozone and humidity on the formation of sulfate and nitrate in airborne fine particles, J. Environ. Sci. Heal. A, 44, 767-777, 2009.

Chang, L., Xu, J., Tie, X., and Wu, J.: Impact of the 2015 El Nino event on winter air quality in China, Scientific Reports, 6, 34275, doi:10.1038/srep34275, 2016.

Gong, S. L. and Zhang, X. Y.: CUACE/Dust - an integrated system of observation and modeling systems for operational dust forecasting in Asia, Atmos. Chem. Phys., 8, 2333-2340, doi:10.5194/acp-8-2333-2008, 2008.

Gong, S. L., Barrie, L. A., Blanchet, J. P., von Salzen K., Lohmann, U., Lesins, G., Spacek, L., Zhang, L. M., Girard, E., Lin, H., Leaitch, R., Leighton, H., Chylek, P., and Huang, P.: Canadian aerosol module: a size-segregated simulation of atmospheric aerosol processes for climate and air quality models - 1. Model development, J. Geophys. Res., 108, 4007, doi:10.1029/2001JD002002, 2003.

Gund, G., Wien, F., and Weisweiler, W.: Oxidation of S02 to sulfate in sea salt aerosols, Fresenius J. Anal. Chem., 340, 616-620, 1991.

Gurjar, B. R., Jain, A., Sharma, A., Agarwal, A., Gupta, P., Nagpure, A. S., and Lelieveld, J.: Human health risks in megacities due to air pollution, Atmos. Environ., 44, 4606-4613, doi:10.1016/j.atmosenv.2010.08.011, 2010.

Han, X., Zhang, M., Tao, J., Wang, L., Gao, J., Wang, S., and Chai, F.: Modeling aerosol impacts on atmospheric visibility in Beijing with RAMS-CMAQ, Atmos. Environ., 72, 177-191, doi:10.1016/j.atmosenv.2013.02.030, 2013.

He, J., Yu, Y., Xie, Y., Mao, H., Wu, L., Liu, N., and Zhao, S.: Numerical model-based artificial neural network model and its application for quantifying impact factors of urban air quality, Water Air Soil Poll., 227, 235, doi:10.1007/s11270-016-2930-z, 2016a.

He, J., Wu, L., Mao, H., Liu, H., Jing, B., Yu, Y., Ren, P., Feng, C., and Liu, X.: Development of a vehicle emission inventory with high temporal-spatial resolution based on NRT traffic data and its impact on air pollution in Beijing - Part 2: Impact of vehicle emission on urban air quality, Atmos. Chem. Phys., 16, 31713184, doi:10.5194/acp-16-3171-2016, 2016b.

He, J., Gong, S., Yu, Y., Yu, L., Wu, L., Mao, H., Song, C., Zhao, S., Liu, H., Li, X., and Li, R.: Air pollution characteristics and their relation to meteorological conditions during 2014-2015 in major Chinese Cities, Environ. Pollut., doi:10.1016/j.envpol.2017.01.050, online first, 2017.

Jia, B., Wang, Y., Yao, Y., and Xie, Y.: A new indicator on the impact of large-scale circulation on wintertime particulate matter pollution over China, Atmos. Chem. Phys., 15, 11919-11929, doi:10.5194/acp-15-11919-2015, 2015.

Kan, H., Chen, R., and Tong, S.: Ambient air pollution, climate change, and population health in China, Environ. Int., 42, 10-19, doi:10.1016/j.envint.2011.03.003, 2012.

Kioutsioukis, I., de Meij, A., Jakobs, H., Katragkou, E., Vinuesa, J., and Kazantzidis, A.: High resolution WRF ensemble forecasting for irrigation: Multi-variable evaluation, Atmos. Res., 167, 156174, doi:10.1016/j.atmosres.2015.07.015, 2016. 
Li, M., Hua, C., and Ma, X.: Analysis of the December 2015 Atmospheric Circulation and Weather, Meteorol. Mon., 42, 382-388, 2016 (in Chinese).

Liao, X., Sun, Z., Tang, Y., Pu, W., Li, Z., and Lu, B.: Meteorological Mechanism for the Formation of a Serious Pollution Case in Beijing in the Background of Northerly Flow at Upper Levels, Environ. Sci., 36, 801-808, doi:10.13227/j.hjkx.2015.03.007, 2015 (in Chinese).

Liu, X., Hu, F., Zou, H., Cao, X., and Dou, J.: Analysis on characteristic of atmospheric boundary layer during a typical heavy fog process in Beijing area, Plateau Meteorol., 29, 1174-1182, 2010 (in Chinese).

Si, D., Liu, Y., Shao, X., and Wang, Y.: Anomalies of Oceanic and Atmospheric Circulation in 2015 and Their Impacts on Climate in China, Meteorol. Mon., 42, 481-488, 2016 (in Chinese).

Sun, Y., Chen, C., Zhang, Y., Xu, W., Zhou L., Cheng, X., Zheng, H., Ji, D., Li, J., Tang, X., Fu, P., and Wang, Z.: Rapid formation and evolution of an extreme haze episode in Northern China during winter 2015, Scientific Reports, 6, 27151, doi:10.1038/srep27151, 2016.

Tang, Y., Li, L., Dong, W., and Wang, B.: Tracing the source of ENSO simulation differences to the atmospheric component of two CGCMs, Atmos. Sci. Lett., 17, 155-161, 2016.

Varotsos, C. A., Tzanis, C. G., and Sarlis, N. V.: On the progress of the 2015-2016 El Niño event, Atmos. Chem. Phys., 16, 20072011, doi:10.5194/acp-16-2007-2016, 2016.

Wang, B., Wu, R., and Fu, X.: Pacific-East Asian teleconnection: how does ENSO affect East Asian climate?, J. Climate, 13, 1517-1536, 2000.

Wang, C., Yang, Y., Li, Y., and Fan, Y.: Analysis on the meteorological condition and formation mechanism of serious pollution in south Hebei Province in January 2013, Res. Environ. Sci., 26, 695-702, doi:10.13198/j.res.2013.07.4.wangcm.006, 2013 (in Chinese).
Wang, H., Gong, S., Zhang, H., Chen, Y., Shen, X., Chen, D., Xue, J., Shen, Y., Wu, X., and Jin, Z.: A new-generation sand and dust storm forecasting system GRAPES_CUACE/Dust: Model development, verification and numerical simulation, Sci. Bull., 55, 635-649, doi:10.1007/s11434-009-0481-z, 2010.

Wang, L., Hao, J., He, K., Wang, S., Li, J., Zhang, Q., Streets, D., Fu, J., Jang, C., Takekawa, H., and Chatani, S.: A Modeling Study of Coarse Particulate Matter Pollution in Beijing: Regional Source Contributions and Control Implications for the 2008 Summer Olympics, J. Air Waste Manage., 58, 1057-1069, doi:10.3155/1047-3289.58.8.1057, 2008.

Wang, L., Wei, Z., Wei, W., Fu, J. S., Meng, C., and Ma, S.: Source apportionment of $\mathrm{PM}_{2.5}$ in top polluted cities in Hebei, China using the CMAQ model, Atmos. Environ., 122, 723-736, doi:10.1016/j.atmosenv.2015.10.041, 2015.

Zeng, J., Wang, M., and Zhang, H.: Correlation between atmospheric $\mathrm{PM}_{2.5}$ concentration and meteorological factors during summer and autumn in Beijing, China, Chinese J. Appl. Ecol., 25, 2695-2699, doi:10.13287/j.1001-9332.20140616.002, 2014 (in Chinese).

Zhang, S., Wu, Y., Wu, X., Li, M., Ge, Y., Liang, B., Xu, Y., Zhou, Y., Liu, H., Fu, L., and Hao, J.: Historic and future trends of vehicle emissions in Beijing, 1998-2020: A policy assessment for the most stringent vehicle emission control program in China, Atmos. Environ., 89, 216-229, doi:10.1016/j.atmosenv.2013.12.002, 2014.

Zhou, C., Gong, S., Zhang, X., Liu, H., Xue, M., Cao, G., An, X., Che, H., Zhang, Y., and Niu, T.: Towards the improvements of simulating the chemical and optical properties of Chinese aerosols using an online coupled model-CUACE/Aero, Tellus B, 64, 18965, doi:10.3402/tellusb.v64i0.18965, 2012. 